Marquette University

e-Publications@Marquette

$11-29-2016$

\title{
Dihedral-Angle-Controlled Crossover from Static Hole Delocalization to Dynamic Hopping in Biaryl Cation Radicals
}

\author{
Marat R. Talipov \\ Marquette University \\ Tushar S. Navale \\ Marquette University \\ Mohammad M. Hossain \\ Marquette University \\ Ruchi Shukla \\ Marquette University \\ Maxim V. Ivanov \\ Marquette University
}

See next page for additional authors

Follow this and additional works at: https://epublications.marquette.edu/chem_fac

Part of the Chemistry Commons

\section{Recommended Citation}

Talipov, Marat R.; Navale, Tushar S.; Hossain, Mohammad M.; Shukla, Ruchi; Ivanov, Maxim V.; and Rathore, Rajendra, "Dihedral-Angle-Controlled Crossover from Static Hole Delocalization to Dynamic Hopping in Biaryl Cation Radicals" (2016). Chemistry Faculty Research and Publications. 565.

https://epublications.marquette.edu/chem_fac/565 


\section{Authors}

Marat R. Talipov, Tushar S. Navale, Mohammad M. Hossain, Ruchi Shukla, Maxim V. Ivanov, and Rajendra Rathore

This article is available at e-Publications@Marquette: https://epublications.marquette.edu/chem_fac/565 


\section{Marquette University}

\section{e-Publications@Marquette}

\section{Chemistry Faculty Research and Publications/Department of Chemistry}

This paper is NOT THE PUBLISHED VERSION; but the author's final, peer-reviewed manuscript. The published version may be accessed by following the link in the citation below.

Angewandte Chemie International Edition, Vol. 56, No. 1 (January 2, 2017): 266-269. DOI. This article is (C) WileyVCH Verlag and permission has been granted for this version to appear in e-Publications@Marquette. Wiley-VCH Verlag does not grant permission for this article to be further copied/distributed or hosted elsewhere without the express permission from Wiley-VCH Verlag.

\section{DIHEDRAL-ANGLE-CONTROLLED CROSSOVER FROM STATIC HOLE DELOCALIZATION TO DYNAMIC HOPPING IN BIARYL CATION RADICALS}

Marat R. Talipov

Department of Chemistry, Marquette University, Milwaukee, WI Tushar S. Navale Department of Chemistry, Marquette University, Milwaukee, WI Mohammad M. Hossain Department of Chemistry, Marquette University, Milwaukee, WI Ruchi Shukla Department of Chemistry, Marquette University, Milwaukee, WI 


\section{Maxim V. Ivanov}

Department of Chemistry, Marquette University, Milwaukee, WI

\section{Rajendra Rathore}

Department of Chemistry, Marquette University, Milwaukee, WI

\section{ABSTRACT}

In cases of coherent charge-transfer mechanism in biaryl compounds the rates follow a squared cosine trend with varying dihedral angle. Herein we demonstrate using a series of biaryl cation radicals with varying dihedral angles that the hole stabilization shows two different regimes where the mechanism of the hole stabilization switches over from (static) delocalization over both aryl rings to (dynamic) hopping. The experimental data and DFT calculations of biaryls with different dihedral angles unequivocally support that a crossover from delocalization to hopping occurs at a unique dihedral angle where the electronic coupling $\left(H_{\mathrm{ab}}\right)$ is one half of reorganization $(\lambda)$, that is, $H_{\mathrm{ab}}=\lambda / 2$. The implication of this finding in non-coherent charge-transfer rates is being investigated.

Biaryl compounds represent the smallest building blocks for exploration of the fundamental properties of the charge transfer in $\pi$-conjugated molecular wires. For example, the angular dependence of the charge transfer in biaryls has been probed by conductance measurements using break-junction techniques. $\frac{1-4}{-}$ These measurements have shown that under coherent transport mechanism the chargetransfer rates scale as the square of the electronic coupling in biaryl compounds, and since the electronic coupling varies with the interplanar dihedral angle $(\phi)$ between the aryl groups, the chargetransfer rates follow a squared cosine trend with $\phi . \frac{5-8}{}$ Importantly, the residence time for the charge onto biaryls is expected to be negligible in coherent charge transport using break-junction techniques. $\underline{2,4}$

Unlike the break-junction techniques, the non-coherent charge transfer through a biaryl linkage would involve a finite residence time onto the biaryl and would depend on the interplay between the electronic coupling and the structural reorganization. In such a charge-transfer scenario, it is unclear how the $\phi$ controls the mechanism of charge stabilization.

In order to address this question, we undertake synthesis and study of a series of biaryls where $\phi$ was varied with a polymethylene chain or tert-butyl groups linked at the 2 and 2 ' positions (Scheme 1 ).

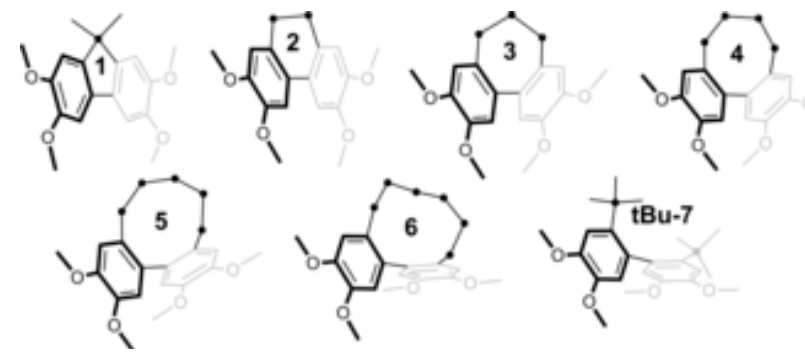


Scheme 1. The structures and naming scheme for biaryls.

Electrochemistry, generation of cation radicals of $\mathbf{1 - 7}$, and their electronic spectroscopy, X-ray crystallography, and DFT calculations allow us to demonstrate for the first time that the stabilization of a cationic charge (hole) in biaryls follow a linear $\cos \phi$ trend only for small angles $\left(\phi=0^{\circ}-45^{\circ}\right)$ and breaks down at larger angles $\left(\phi>45^{\circ}\right)$ due to a crossover of the hole stabilization mechanism from (static) delocalization to (dynamic) hopping. We will demonstrate that the crossover occurs due to the interplay between electronic coupling, which varies with $\phi$ and the structural/solvent reorganization. Details of these findings are described herein.

Biaryls 1-6 and ${ }^{\text {t }} \mathrm{Bu}-\mathbf{7}$ (7) were synthesized by adopting the literature procedures, $\frac{9-11}{}$ and the experimental details including X-ray structural data of 1-4 are compiled in the Supporting Information. The X-ray structures of 1-4 were accurately reproduced by DFT calculations [B1LYP-40/6-31G(d)+ $\left.\mathrm{PCM}\left(\mathrm{CH}_{2} \mathrm{Cl}_{2}\right)\right]^{12-16}$ (Figure S7). However, for higher homologues 4-6, conformational search revealed the presence of multiple conformers (Tables S10, S11). In order to establish the true identity of the conformations of 2-7 in solution, we resorted to ${ }^{1} \mathrm{H}$ NMR spectroscopy.

The ${ }^{1} \mathrm{H}$ NMR chemical shifts of aromatic protons are highly sensitive to the dihedral angle $\phi$ in biaryls. ${ }^{17}$ The chemical shieldings of the 2,2'-aryl protons for all possible conformations of 1-7 were determined using a gauche-independent atomic orbital (GIAO) approach (see the Supporting Information for details). The linear relationship between computed chemical shieldings of 2,2'-protons of the lowestenergy conformer against the experimental chemical shifts (Figure $\underline{1} \mathrm{~A}$ ) establishes the conformational identity of 1-7 in solution, as depicted in Figure $\underline{1}$ B.

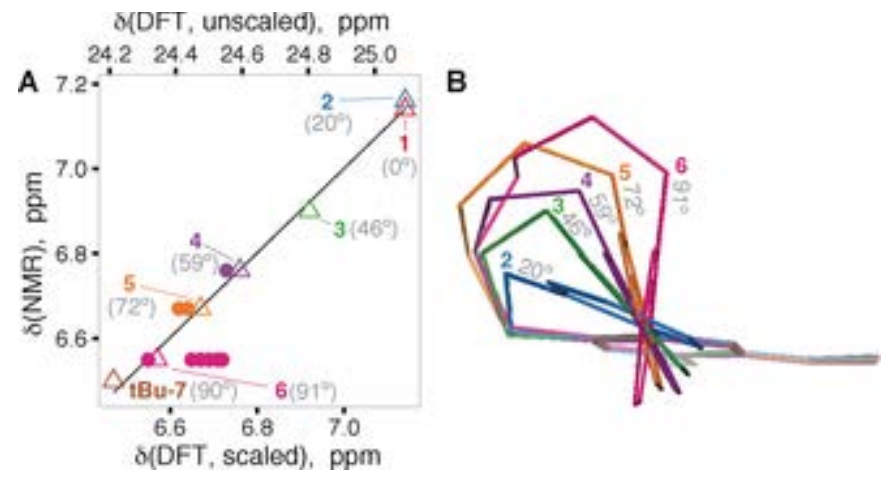

Figure 1. A) ${ }^{1} \mathrm{H}$ NMR chemical shift of 2,2'-protons of 1-7 plotted against the calculated/scaled (top/bottom axis) chemical shifts. The lowest-/highest-energy conformers of 4-6 are shown by empty triangles/filled circles. B) Superposition of the structures of 2-6 showing the variation in dihedral angles with increasing number of methylenes. Methoxy groups on one of aryl rings are omitted for clarity.

Reversible cyclic voltammograms of 1-7 provide the oxidation potentials (Figure $\underline{2}$ A), which show an increase of about $0.5 \mathrm{~V}$ going from a planarized (i.e. 1, $\phi=0^{\circ}$ ) to perpendicularly oriented biaryls (i.e. 6 and $7, \phi$ ca. $\left.90^{\circ}\right)$. Interestingly, the $E_{\text {ox } 1}$ of biaryls with $\varphi \simeq 90^{\circ}(6: 0.83 \mathrm{~V}, 7: 0.87 \mathrm{~V})$ were similar to $E_{\mathrm{ox} 1}$ of the corresponding model arenes, that is, 3,4-dimethoxytoluene ( $\left.E_{\mathrm{ox} 1}=0.87 \mathrm{~V}\right)[\underline{9}]$ and 3,4-dimethoxy1-tert-butylbenzene $\left(E_{\mathrm{ox} 1}=0.90 \mathrm{~V}\right) . \underline{18}$ 

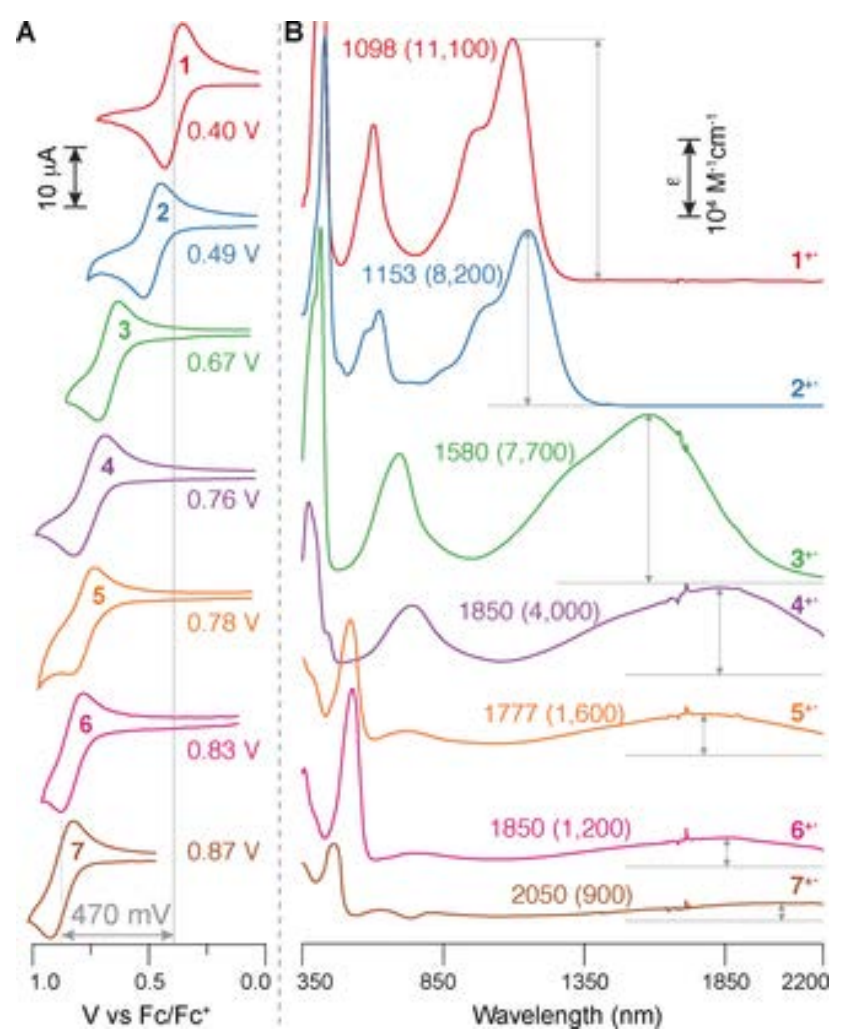

Figure 2. A) Cyclic voltammograms (CVs) of $2 \mathrm{~mm} \mathrm{1-7} \mathrm{in} \mathrm{CH}_{2} \mathrm{Cl}_{2}\left(0.1 \mathrm{~m} \mathrm{n}-\mathrm{Bu}_{4} \mathrm{NPF}_{6}\right)$ at a scan rate of $200 \mathrm{mV} \mathrm{s}^{-1}$ and $22{ }^{\circ} \mathrm{C}$. The value of $E_{\mathrm{ox} 1}$ (vs. $\mathrm{Fc} / \mathrm{Fc}^{+} ; \mathrm{Fc}=$ ferrocene) is indicated in each $\mathrm{CV}$. B) The absorption spectra of $\mathbf{1}^{+}-\mathbf{7}^{+}$. in $\mathrm{CH}_{2} \mathrm{Cl}_{2}$ at $22^{\circ} \mathrm{C}$. The position of lowest-energy band (in $\mathrm{nm}$ ) and molar absorptivity (in $\mathrm{M}^{-1} \mathrm{~cm}^{-1}$ ) are shown on each spectrum.

The cation radicals of 1-7 were generated by quantitative redox titrations using $\mathrm{THE}^{+} \cdot \mathrm{SbCl}_{6}{ }^{-}$ (THE=1,2,3,4,5,6,7,8-octa-hydro-9,10-dimethoxy-1,4:5,8-dimethanoanthracene, $E_{\text {red }}=0.67 \mathrm{~V}, \lambda_{\max }=518$ $\left.\mathrm{nm}, \epsilon_{\max }=7300 \mathrm{~cm}^{-1} \mathrm{~m}^{-1}\right) \underline{19}$ and $\mathrm{NAP}^{+} \cdot \mathrm{SbCl}_{6}{ }^{-}$(NAP=1,2,3,4,7,8,9,10-octahydro-1,1,4,4,7,7,10,10octamethylnaphtacene, $E_{\text {red }}=0.94 \mathrm{~V}, \lambda_{\max }=672 \mathrm{~nm}, \epsilon_{\max }=9300 \mathrm{~cm}^{-1} \mathrm{~m}^{-1}$ ) as aromatic oxidants. $\underline{20,21}$ The redox titrations were performed by an incremental addition of a neutral biaryl to a solution of $\mathrm{THE}^{+}$(or $\mathrm{NAP}^{+}$) in $\mathrm{CH}_{2} \mathrm{Cl}_{2}$ at $22^{\circ} \mathrm{C}$, and the resulting absorption spectra were quantitatively analyzed (section S4

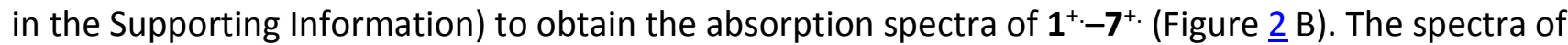

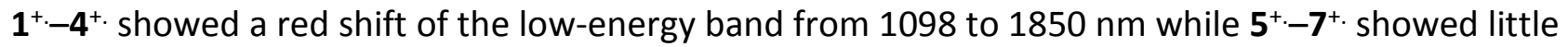
variance in the position of the low-energy band, but rather a dramatically reduced molar absorptivity for the near-infrared band decreasing from $4^{+\cdot}$ to $7^{+}$(Figure $\underline{2} \mathrm{~B}$ ).

The X-ray crystallography of representative cation radicals $\left({ }^{+} \cdot \mathrm{SbCl}_{6}{ }^{-}\right.$and $\left.3^{+} \cdot \mathrm{SbCl}_{6}{ }^{-}\right)$shows considerable oxidation-induced bond-length changes in the biaryls, especially in the central aryl-aryl C-C bond (by $0.036 \AA$ and $0.022 \AA$, respectively). See the Supporting Information for detailed analysis of the $X$-ray structures and ORTEP diagrams. The dihedral angle between the aryl moieties in $3^{+.}\left(\phi_{C R} ; 25^{\circ}\right)$ showed an oxidation-induced decrease of ca. $10^{\circ}$. 
The DFT calculations [B1LYP-40/6-31G(d)+PCM $\left(\mathrm{CH}_{2} \mathrm{Cl}_{2}\right)$ ] accurately reproduced the available X-ray structures and dihedral angles for neutral (i.e. $\phi$ ) and cation radicals (i.e. $\phi_{\mathrm{CR}}$ ) of biaryls (Tables S7, S8 and Figures S8, S9). The (TD-)DFT calculations of the structures of neutral and cation radicals of 1-7 reproduced the experimental $E_{\mathrm{ox} 1}$ and the excitation energies for the lowest-energy transition in $\mathbf{1}^{+}-\mathbf{7}^{+}$. (Figure S11). The calculated dihedral angles in the biaryl cation radicals show an oxidation-induced decrease of $4-19^{\circ}$ (Table S11), and the most pronounced changes in the dihedral angle were observed with $4^{+\cdot-6^{+}}$owing to the flexibility of the polymethylene linker (Figure 1 ).

A comparison of the structures of neutral 1-7 and their cation radicals shows that the central aryl-aryl $\mathrm{C}-\mathrm{C}$ bond in $\mathbf{1}^{+\cdot}-\mathbf{7}^{+}$. experiences the most notable shortening and variation with the dihedral angle $\phi_{\mathrm{CR}}$ (i.e. $\mathbf{2}^{+.}: 16^{\circ}, \mathbf{3}^{+.}: 36^{\circ}, \mathbf{4}^{+.}: 45^{\circ}, \mathbf{5}^{+.}: 53^{\circ}, \mathbf{6}^{+. .}: 74^{\circ}, \mathbf{7}^{+.}: 88^{\circ}$ ) as depicted in Figure $\underline{3}$.

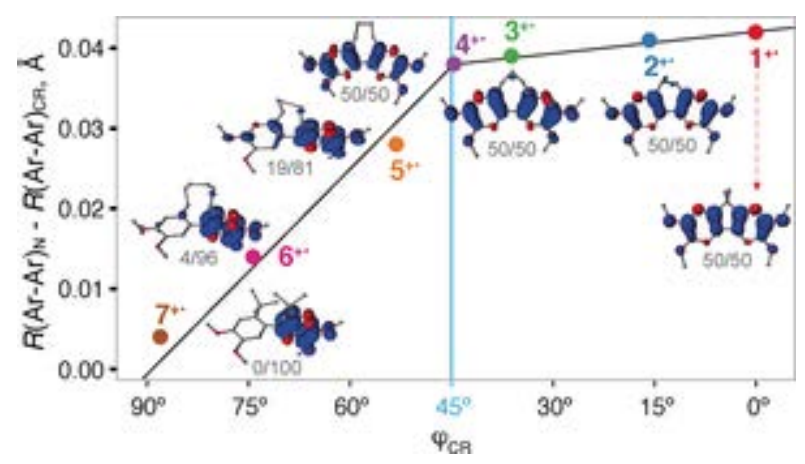

Figure 3. Changes in the oxidation-induced central aryl-aryl $\mathrm{C}-\mathrm{C}$ bonds in various biaryls cation radicals against $\phi_{\mathrm{CR}}$ and the corresponding isovalue $( \pm 0.003 \mathrm{au})$ plots of spin-density distribution. The fraction of spin/charge distribution per aryl moiety, obtained by the natural population analysis, $\underline{22,23}$ is indicated below the structures. A vertical line at $45^{\circ}$ separates biaryls with completely delocalized $\left(\mathbf{1}^{+}-\mathbf{4}^{+}\right)$versus partially/fully localized charge $\left(5^{+}-7^{+}\right)$.

Most importantly, Figure $\underline{3}$ shows that the biaryls with dihedral angles $\phi_{\mathrm{CR}}=0-45^{\circ}$ (i.e. $\mathbf{1}^{+}-\mathbf{4}^{+}$) exhibit (almost) identical oxidation-induced central C-C bond contraction $(0.04 \pm 0.002 \AA)$ and a complete delocalization of the hole over both aryl moieties. In contrast, biaryls with a larger dihedral angle $\phi_{\mathrm{CR}}>45^{\circ}$ show a systematic decrease in the $\mathrm{C}-\mathrm{C}$ bond shortening with increasing $\phi_{\mathrm{CR}}$, that is, $0.028 \AA$ in $\mathbf{5}^{+}, 0.014 \AA$ in $\mathbf{6}^{+}$, and $0.004 \AA$ in $\mathbf{7}^{+}$and a concomitant increase in the localization of the spin/charge on a single aryl moiety (Figure $\underline{3}$ ). This surprising observation of two different regimes based on dihedral angle, that is, complete versus partial charge delocalization on two aryl moieties in biaryl cation radicals, suggests that a change occurs in the mechanism of charge delocalization/stabilization.

Supporting this view, plots of experimental $E_{\mathrm{ox} 1}$ and $v_{\max }$ of $\mathbf{1}^{+\cdot}-\mathbf{7}^{+}$, shown in Figure 4 , also reveal two different trends in the range of $0-45^{\circ}$ and $45-90^{\circ}$, where the biaryl with $\phi_{\mathrm{CR}}$ about $45^{\circ}$ represents a crossover point (see Figure 4 ). Excitation energies for the $D_{0} \rightarrow D_{1}$ transition in biaryls $\mathbf{1}^{+\cdot}-\mathbf{4}^{+}$. in the " 0 $45^{\circ}$ regime" show a linear red shift against $\cos \left(\phi_{\mathrm{CR}}\right)$, and the nature of this electronic transition is consistent with completely delocalized ground and excited states (Figure $\underline{5}$ ). The position of the $D_{0} \rightarrow D_{1}$ transition in $\mathbf{5}^{+-}-\mathbf{7}^{+}$. in the "45-90 regime" remains largely unchanged except reduced molar absorptivity with increasing $\phi_{\mathrm{CR}}$, and the corresponding electronic transition was shown to have a 
charge-transfer character (Figure $\underline{5}$ ). The cation radical ${ }^{t} \mathrm{Bu}-7^{+} \cdot$ with $\phi_{\mathrm{CR}}$ about $90^{\circ}$ shows that the charge is fully localized onto one unit with extremely weak $D_{0} \rightarrow D_{1}$ transition of charge-transfer character (Figure $\underline{5}$ ). The observed angular dependence of redox and optical properties of $\mathbf{1}^{+}-\mathbf{7}^{+}$. (Figure $\underline{4}$ ) and analysis of the nature of the $D_{0} \rightarrow D_{1}$ transitions (Figures $\underline{5}$ and S15) clearly suggests that there is crossover from delocalization to hopping mechanism that depends on a dihedral angle.
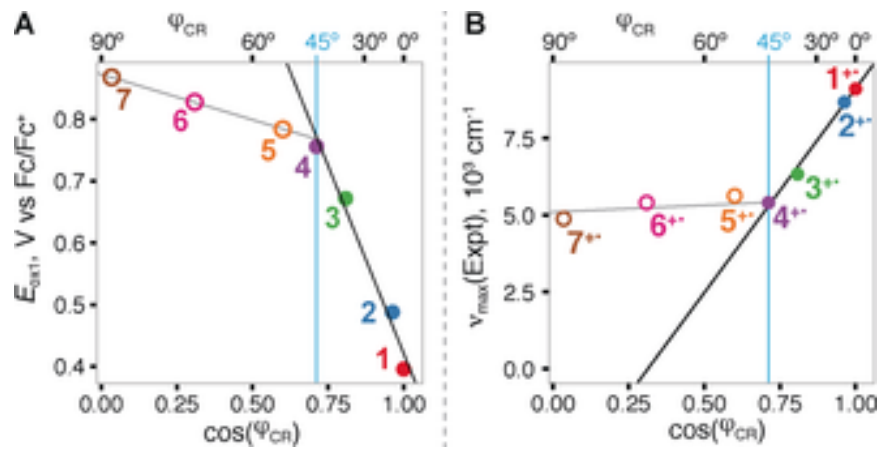

Figure 4. Plots of $E_{\text {ox } 1}$ of $1-7(A)$ and $v_{\max }$ of $\mathbf{1}^{+}-\mathbf{7}^{+}$. (B) against $\cos \left(\phi_{\mathrm{CR}}\right)$. A vertical line at $45^{\circ}$ separates biaryls with different linear trends, that is, $\mathbf{1}^{+} \cdot \mathbf{4}^{+}$. (full circles) versus $\mathbf{5}^{+\cdot}-\mathbf{7}^{+.}$(empty circles).

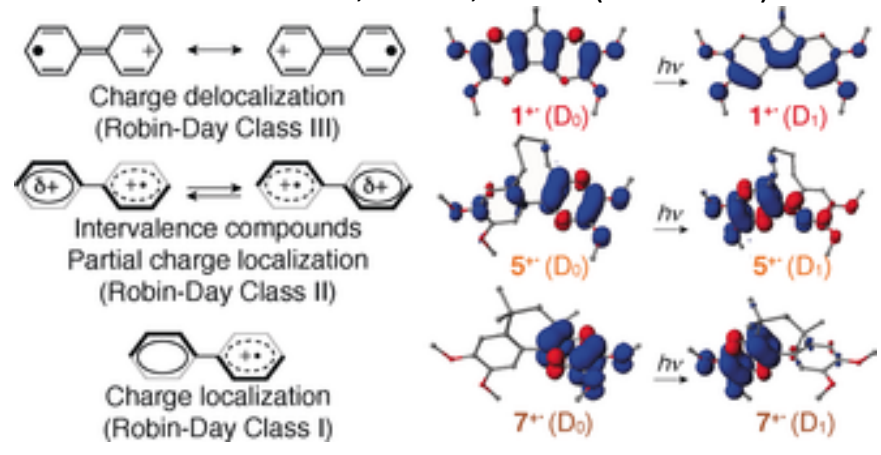

Figure 5. Typical examples of complete delocalization to partial or full localization and nature of the accompanying electronic transition, as shown by isovalue plots ( $\pm 0.003 \mathrm{au}$ ) of spin-density distributions.

As the biaryls 1-7 do not probe the entire continuum of dihedral angles, we carried out a systematic computational scan on a model biaryl cation radical (Figure $\underline{6}$ ), where a series of constrained optimizations with fixed $\phi_{\mathrm{CR}}$ and subsequent TD-DFT calculations provided the excitation energies $\left(v_{\max }\right)$ at different dihedral angles $\phi$ (see Figure $\underline{6}$ ). $\underline{.4}$

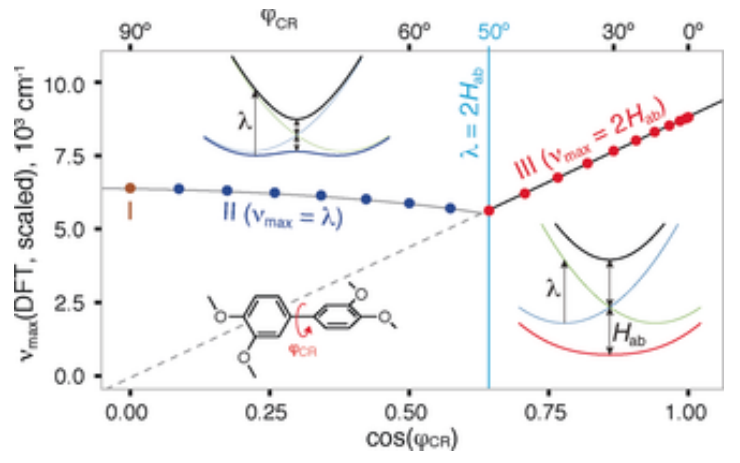

Figure 6. A plot of $v_{\max }$ against $\cos \left(\phi_{\mathrm{CR}}\right)$, obtained from the scan on a model biaryl (structure shown) with the $\phi_{\mathrm{CR}}$ step size of $5^{\circ}$ [TD-B1LYP-40/6-31G(d)+PCM $\left(\mathrm{CH}_{2} \mathrm{Cl}_{2}\right)$ ]. The $v_{\max }$ were scaled according to linear trend with 
experiment (Figure S11B, Supporting Information). The two distinct regions, separated by a blue line, are identified using Marcus two-state model where $H_{\mathrm{ab}}$ is the electronic coupling between (charge-localized) diabatic states and $\lambda$ is the structural/solvent reorganization parameter. $\underline{25}$

Because the electronic coupling $H_{\mathrm{ab}}$ scales linearly with $\cos \left(\phi_{\mathrm{CR}}\right), \underline{26,27}$ the computed $v_{\max }$ in the model biaryl also follow a linear dependence with $\cos \left(\phi_{\mathrm{CR}}\right)$ in $0-50^{\circ}$ range (Figure $\underline{6}$, red symbols) in accordance with Marcus two-state model for fully delocalized systems (Figure $\underline{6}$, bottom right). In contrast, the crossover from the linear $v_{\max } / \cos \left(\phi_{\mathrm{CR}}\right)$ trend in model biaryl with $\phi>50^{\circ}$ is surprising considering that the electronic coupling $H_{\mathrm{ab}}$ continues to decrease linearly with $\cos \left(\phi_{\mathrm{CR}}\right)$. The invariance of $v_{\max }$ with the increasing $\phi_{\mathrm{CR}}$ (Figure $\underline{6}$, blue symbols) signifies, based on the Marcus model (Figure $\underline{6}$, top left), that the charge transfer occurs by the hole hopping and thereby $v_{\max }$ directly provides the value of reorganization energy, that is, $v_{\max }=\lambda . \underline{25}$ Thus, the interplay between the invariant $\lambda$ and decreasing $H_{a b}$ in model biaryl with $\phi>50^{\circ}$ represents the cases where $2 H_{a b}<\lambda$, that is, hole distribution switches over from complete delocalization over both aryl units (i.e. $2 H_{a b} \geq \lambda$ ) to partial and then full hole localization onto a single aryl unit. The crossover point in such a system is thus expected to occur when $2 \mathrm{Hab}_{\mathrm{a}} \lambda$ (Figure $\underline{4} \mathrm{~B}$ ). Interestingly, the crossover point of $50^{\circ}$ obtained by computational scan of a model biaryl is rather similar to the experimental crossover point of about $45^{\circ}$ observed for biaryls 1-7 (compare Figure $\underline{4}$ B and Figure $\underline{6}$ ).

In summary, we have demonstrated for the first time using a well-defined series of biaryl cation radicals with varied interplanar dihedral angles that a crossover occurs from a fully delocalized regime to a mixed-valence regime because of the interplay between the electronic coupling and reorganization energy. The observation of a crossover point between two regimes is expected because it represents a unique point where the reorganization energy is exactly one half of the electronic coupling, that is, $H_{a b}=\lambda / 2$.

Thus, the linear dependence of charge-transfer rates against $\cos ^{2} \phi$ trend $\underline{28}$ over the entire range of dihedral angles under a coherent tunneling mechanism should be contrasted with non-coherent mechanism, where the hole stabilization mechanism changes from (static) delocalization to (dynamic) hopping at a unique dihedral angle. Note that such crossover dihedral angle must satisfy the condition of $H_{a b}=\lambda / 2$ and therefore the crossover angles will be different for different molecules owing to the varied reorganization energies and electronic couplings. The studies of non-coherent charge-transfer rates will be undertaken using donor-biaryl-acceptor triads with varied dihedral angles in order to demonstrate the implication of the crossover of the hole stabilization mechanism from delocalization to hopping.

\section{CONFLICT OF INTEREST}

The authors declare no conflict of interest. 


\section{ACKNOWLEDGEMENTS}

We thank NSF (CHE-1508677) and NIH (R01-HL112639-04) for financial support, Dr. Sergey V. Lindeman for X-ray crystallography, and Professors James Gardinier and Scott Reid for helpful discussions. The calculations were performed on the Père cluster (Marquette University) and XSEDE (NSF, TG-CHE130101).

\section{ANCILLARY}

\section{SUPPORTING INFORMATION}

${ }^{1}$ D. Vonlanthen, A. Mishchenko, M. Elbing, M. Neuburger, T. Wandlowski, M. Mayor, Angew. Chem. Int. Ed. 2009, 48, 8886; Wiley Online Library I CAS | Angew. Chem. 2009, 121, 9048. Wiley Online Library |

${ }^{2}$ A. Mishchenko, D. Vonlanthen, V. Meded, M. Burkle, C. Li, I. V. Pobelov, A. Bagrets, J. K. Viljas, F. Pauly, F. Evers, Nano Lett. 2009, 10, 156. CrossRef | CAS | ADS |

${ }^{3}$ L. Cui, B. Liu, D. Vonlanthen, M. Mayor, Y. Fu, J.-F. Li, T. Wandlowski, J. Am. Chem. Soc. 2011, 133, 7332. CrossRef | PubMed | CAS |

${ }^{4}$ L. Venkataraman, J. E. Klare, C. Nuckolls, M. S. Hybertsen, M. L. Steigerwald, Nature 2006, 442, 904. CrossRef I PubMed $|\underline{\text { CAS }}| \underline{\text { ADS }}$ |

${ }^{5}$ A. Heckmann, C. Lambert, Angew. Chem. Int. Ed. 2012, 51, 326; Wiley Online Library | CAS | Angew. Chem. 2012, 124, 334. Wiley Online Library |

${ }^{6}$ D. Hanss, O. S. Wenger, Eur. J. Inorg. Chem. 2009, 3778. Wiley Online Library I

${ }^{7}$ K. E. Spettel, N. H. Damrauer, J. Phys. Chem. C 2016, 120, 10815. CrossRef I CAS I

${ }^{8}$ A. C. Benniston, A. Harriman, Chem. Soc. Rev. 2006, 35, 169. CrossRef I PubMed I CAS I

${ }^{9}$ L. Zhai, R. Shukla, S. H. Wadumethrige, R. Rathore, J. Org. Chem. 2010, 75, 4748. CrossRef | PubMed | CAS |

${ }^{10}$ L. Zhai, R. Shukla, R. Rathore, Org. Lett. 2009, 11, 3474. CrossRef I PubMed I CAS I

${ }^{11}$ R. Shukla, R. Rathore, Synthesis 2008, 3769.

${ }^{12}$ M. R. Talipov, A. Boddeda, S. V. Lindeman, R. Rathore, J. Phys. Chem. Lett. 2015, 6, 3373. CrossRef | PubMed | CAS I

${ }^{13}$ M. R. Talipov, T. S. Navale, R. Rathore, Angew. Chem. Int. Ed. 2015, 54, 14468-14472; Wiley Online Library I CAS | Angew. Chem. 2015, 127, 14676-14680. Wiley Online Library |

${ }^{14}$ M. R. Talipov, R. Jasti, R. Rathore, J. Am. Chem. Soc. 2015, 137, 14999. CrossRef | PubMed | CAS |

${ }^{15}$ M. R. Talipov, A. Boddeda, Q. K. Timerghazin, R. Rathore, J. Phys. Chem. C 2014, 118, 21400. CrossRef | CAS |

${ }^{16}$ M. R. Talipov, M. V. Ivanov, R. Rathore, J. Phys. Chem. C 2016, 120, 6402. CrossRef | CAS |

${ }^{17}$ R. B. Bates, F. A. Camou, V. Kane, P. K. Mishra, K. Suvannachut, J. J. White, J. Org. Chem. 1989, 54, 311. CrossRef | CAS |

${ }^{18}$ See CVs in the Supporting Information.

${ }^{19}$ R. Rathore, C. L. Burns, M. I. Deselnicu, Org. Synth. 2005, 1.

${ }^{20}$ R. Rathore, J. K. Kochi, Acta Chem. Scand. 1998, 52, 114. CrossRef | CAS |

${ }^{21}$ R. Rathore, C. L. Burns, M. I. Deselnicu, Org. Lett. 2001, 3, 2887. CrossRef | PubMed | CAS |

${ }^{22}$ A. E. Reed, L. A. Curtiss, F. Weinhold, Chem. Rev. 1988, 88, 899. CrossRef | CAS |

${ }^{23} \mathrm{~F}$. Weinhold, C. R. Landis in Valency and bonding: a natural bond orbital donor-acceptor perspective, Cambridge University Press, Cambridge, 2005. CrossRef I

${ }^{24}$ Compare the plot of calculated $v_{\max }$ of different conformers of $\mathbf{1}^{+} \cdot \mathbf{7}^{+}$against the $\cos \left(\varphi_{\mathrm{CR}}\right)$ in Figure S12 in Supporting Information with Figure 6.

${ }^{25}$ B. S. Brunschwig, C. Creutz, N. Sutin, Chem. Soc. Rev. 2002, 31, 168. CrossRef | PubMed | CAS |

${ }^{26}$ R. S. Mulliken, J. Chim. Phys. Phys.-Chim. Biol. 1949, 46, 497. 
${ }^{27}$ G. D. Scholes, R. D. Harcourt, K. P. Ghiggino, J. Chem. Phys. 1995, 102, 9574. CrossRef | CAS | ADS | ${ }^{28}$ In case of coherent tunneling charge-transfer mechanism, the rate of the charge transfer in biaryls is proportional to square of the coupling and, therefore, varies linearly with $\cos ^{2} \varphi$, see Refs. $[2,4,25]$. 